\title{
Insecticidal Properties and Chemical Composition of Conyza Aegyptiaca (L.) Oil: Studies on Two Dipterous Insect Pests
}

\author{
Sameeh A. Mansour* and Reham I. Mohamed \\ Environmental Toxicology Research Unit (ETRU), Pesticide Chemistry Department, National Research Centre, Dokki, \\ Cairo, Egypt
}

\begin{abstract}
The herb, Conyza aegyptiaca L., was subjected to hydrodistillation process to extract the essential oil from the whole dry plant material. Larvae and adult stages of the mosquito, Anopheles pharoensis, and the housefly, Musca domestica, were used as test model organisms representing two dipterous insect pests of medical importance. Under standard bioassay test methods, the LC50 of the oil accounted to $37.8 \mathrm{ppm}$ and $0.087 \mathrm{mg} / \mathrm{cm}^{2}$ against larvae and adults of $A n$. pharoensis, respectively. These toxicity parameters were found to be $71.8 \mathrm{ppm}$ as LC50 and $0.125 \mu \mathrm{g} / \mathrm{insect}$ as LD50 against larvae and adults of $M$. domestica, respectively. Using GC/MS analysis, we identified 19 compounds constituting ca. $97 \%$ of phytochemicals present in the oil, such as monoterpenes, sesquiterpenes and esters. Limonene constituted about $50 \%$ of the plant oil (48.79\%), followed by (E) - $\beta$-Ocimene $(8.66 \%)$, Germacrene D (7.54\%) and $\beta$-pinene (6.91\%). The occurrence of the other constituents ranged between $0.27 \%$ and $5.29 \%$. It was concluded that the potency of C. aegyptiaca oil refers mainly to the presence of limonene. The findings of this study may encourage more research aiming at investigation of eco-friendly biopesticides based on botanical resources.
\end{abstract}

Keywords: Conyza aegyptiaca, Essential oil, Limonene, Mosquitoes, Housefly.

\section{INTRODUCTION}

The order Diptera presents an array of insects which being more than any other group poses the greatest challenge to human and veterinary health as vectors of diseases. One such insects, which share a close ecological niche with man is the house fly, Musca domestica Linnaeus (Diptera: Muscidae). Apart from disease transmission, M. domestica soils man's food and usually constitutes a nuisance, particularly the adult stage [1]. House flies, occur throughout the tropics and are also found in warm temperate regions and some cooler areas. It is recognized as a serious public health pest to human beings and livestock by transmitting many infectious diseases causing a serious threat to human and livestock by vectoring several pathogenic organisms such as protozoa cysts, helminth parasites, enteropathogenic bacteria, and enterovirus [2-5].

Also, mosquitoes are responsible for the biological transmission of several diseases like filariasis, dengue fever, Japanese encephalitis and malaria. Despite an array of control measures taken to suppress mosquito populations, they continue to flourish and contribute to high human mortalities, particularly in developing countries [6].

Indeed, the use of insecticides remains the first line of defense against herbivorous insects, nematodes, plant

*Address correspondence to this author at the Environmental Toxicology Research Unit (ETRU), Pesticide Chemistry Department, National Research Centre, Dokki, Cairo, Egypt; Tel: (202) 33371211; Fax: (202) 33370931;

E-mail: samansour@hotmail.com pathogens and insect vectors of disease. Control measure against these insects in the short-term still depends on the use of conventional insecticides $[7,8]$. The indiscriminate use of chemical insecticides has given rise to many wellknown and serious problems, such as the risk of developing insect resistance and insecticidal residual for humans and the environment [9]. Insecticide resistance in house fly and mosquitoes is a global problem and several surveys have shown that such resistance is wide spread and increasing [10, 11]. These problems coupled with the high cost of chemical pesticides have stimulated the search for biologically based alternatives. Accordingly, botanical insecticides based on natural compounds from plants, are expected to be a possible alternative. They tend to have broad-spectrum activity, relative specificity in their mode of action, and easy to process and use. They also tend to be safe for animals and the environment [12]. Specifically, many studies have drawn attention to the toxic effects of plant extracts on related Diptera $[8,13,14]$.

Our concern here is directed to one candidate plant of the Asteraceae family, Conyza aegyptiaca L. The genus Conyza (Asteraceae) is an annual, biennial or perennial herbaceous plant. It consists of $80-100$ species growing in tropical and subtropical areas of the world $[15,16]$. C. aegyptiaca is an aromatic herb mainly distributed in Africa, tropical Asia and Australia [16]. The plant is used in folk medicine as an anthelmintic, a body-wash for convalescents, and a soothing for skin diseases [17]. Previous pharmacological studies have shown that its polar extracts possess antiviral and antimicrobial activities [18]. 
Recent studies were conducted in our laboratory [19-21] to screen the insecticidal activities against the mosquito, Anopheles pharoensis and the housefly, Musca domestica for ethanolic crude extracts of some plant species including $C$. aegyptiaca. To the best of our knowledge, however, except our previous studies, the literature offers no data on the insecticidal activity of $C$. aegyptiaca against the above mentioned insects. Also, there are no data on the efficacy of its essential oil against mosquitoes and housefly. Therefore, in continuation to our goals, the current work was undertaken to estimate toxicity of the essential oil against larval and adult stages of the mosquito, Anopheles pharoensis and the housefly, Musca domestica. Also, to identify the oil constituents that may responsible for its insecticidal activity.

\section{MATERIALS AND METHODS}

\section{Plant}

The herb (C. aegyptiaca L.) was collected from road side at $6^{\text {th }}$ October City, Giza, Egypt and authenticated by Prof. M. El- Gebaly, Flora Dept., National Research Centre, Cairo, Egypt. The fresh herb was washed, air dried, powdered and kept in dark glass bottle until used for extraction.

\section{Test Insects}

Anopheles pharoensis: An. pharoensis were reared under standard conditions at $27^{\circ} \mathrm{C}, 70 \%$ relative humidity and a 12L: 12D photoperiod. Eggs were placed in plastic trays filled with distilled water. Larvae were reared at a fixed density of 100 larvae per tray and fed upon tetramine, which is recommended for larval development and female fecundity [22]. Pupae were collected from day 11 to 15 , placed in emergence cages of $50 \times 50 \times 50 \mathrm{~cm}$ and provided with a piece of sponge supplied with $10 \%$ glucose solution that was suspended by a wire thread from the roof of the cage. Adult females were fed on pigeons. The eggs laid were transferred to small plastic containers filled with distilled water and a small amount of tetramine. After breeding for several generations, $4^{\text {th }}$ instar larvae as well as 5 -day-old female adults were selected for running bioassay tests.

Musca domestica:Musca domestica (MD) house flies were reared in the insect rearing room of our laboratory at $25-27^{\circ} \mathrm{C}$, and $55-60 \%$ relative humidity. A standard rearing method [23] was adapted to provide 3rd larval instars and adult flies of $0-24 \mathrm{hrs}$ old for running bioassay tests.

\section{Extraction of Plant Oil}

Volatile oil was obtained by hydrodistillation using Clevenger apparatus [24]. Hundred grams of dried whole plant material of C. aegyptiaca were powdered and placed in a $2 \mathrm{~L}$ flask filled till its half with tap water and distilled over an electric sand path. At the end of distillation (usually 3$5 \mathrm{hrs}$.) the sand path was shut off and the resulted oil was withdrawn from the apparatus tap in a small vial, dried over anhydrous sodium sulfate for removing any water droplets, filtered, weighed and kept in a deep freezer $\left(-18^{\circ} \mathrm{C}\right)$ till used in bioassay tests and phytochemical analysis.

\section{Toxicity Bioassay}

\section{Tests with mosquitoes}

a. Larvicidal Activity. Standard methods for testing the susceptibility of mosquito larvae to insecticides [25] were followed with minor modifications. A series of 7 concentrations of the tested oil were prepared in $250 \mathrm{ml}$ glass beakers, marked at $100 \mathrm{ml}$ level, each containing ca. $90 \mathrm{ml}$ of distilled water. The desired amounts of oil were added to the beakers followed with few drops of Tween-80 to facilitate solubility of oil. Ten newly moulted $4^{\text {th }}$ instar larvae of Anopheles pharoensis were transferred to each beaker in least quantity of water by means of a small dropper, and then the solution level was adjusted to the $100 \mathrm{ml}$ mark. This process was repeated in three other beakers for each tested concentration. In control experiments, plain water containing few drops of Tween- 80 was used. All beakers were incubated at room temperature for $24 \mathrm{~h}$ and then mortality was recorded. Percentage mortalities were corrected according to Abbott's formula [26]. The probit analysis was used to estimate toxicity values (e.g., LC50 \& LC95 values), as well as the slope of regression lines according to Finney [27]; using LD-P Software program.

b. Adulticidal Activity: The test was conducted by dissolving a definite amount of the plant oil ( 0.0 up to 12.0 $\mathrm{mg}$ ) in $2 \mathrm{ml}$ acetone and spread on the surface of a strip of filter paper of $15 \times 5 \mathrm{~cm}$ size equivalent to a concentration of $\left(0.0\right.$ up to $\left.0.16 \mathrm{mg} / \mathrm{cm}^{2}\right)$. After drying, the strip was rolled inside a glass vial of $8 \times 5 \mathrm{~cm}$ size. Ten females of An. pharoensis (5-days-old) were anaesthetized by $\mathrm{CO}_{2}$ and transferred to the vial by aspirator, and then the vial was covered. After recovery (about 20 $\min$.), the females were allowed to be in contact with the strip for $1 \mathrm{~h}$. Control tests were carried out in the same manner but the filter paper was impregnated with $2 \mathrm{ml}$ acetone free of plant oil (i.e., 0.0 concentration). After the specified duration $(1 \mathrm{~h})$ the adult females were transferred into wooden cages $(20 \times 20 \times 20 \mathrm{~cm})$, containing cotton pieces soaked with water, and the percent kill was recorded after $24 \mathrm{~h}$. The mortality was adjusted by Abbott's formula [26], and the toxicity values were estimated according to Finney [27]; using LD-P Software program. Usually, a series of 7 concentrations were prepared to estimate the toxicity values. The procedure used was that of Wright [25].

\section{Tests with Housefly}

a. Larvicidal Activity. Standard methods for the evaluation and testing of new insecticides [25] were followed with minor modifications. Larvicidal tests were based on exposing M. domestica (MD) larvae to food-contaminated with toxicants (i.e., "bait"). The bait was prepared by mixing $2 \mathrm{~g}$ coarse wheat bran with $2 \mathrm{ml}$ water containing the tested oil. Third larval instars of MD were allowed to feed on batches of freshly prepared baits placed in $250 \mathrm{ml}$ - glass bakers; each provided with 10 larvae. Eight concentrations of 4 replicates each were usually tested for the plant oil along with control treatment containing bait free of plant oil. All beakers were 
incubated at room temperature for $24 \mathrm{~h}$, then percent mortalities were estimated and corrected according to Abbott's formula [26]. Probit analysis [27] was performed to estimate toxicity values (e.g., LC50 \& LC95) and slope of regression lines; using LD-P Software program.

b. Adulticidal Activity. Standard methods for the evaluation and testing of new insecticides by topical application [25] were followed with minor modifications. The houseflies were anaesthetized with diethyl ether for 5 minutes where $1 \mu \mathrm{l}$ of the test solution was applied by a Clinical Series pipette (CSP) on the dorsal thorax of 0 $24 \mathrm{~h}$-old adult housefly of mixed sexes selected randomly. Ten insects were used for each concentration. Eight concentrations of 4 replications each were usually tested along with control treatments dosed with solution free of the tested oil. All beakers were incubated at room temperature for $24 \mathrm{~h}$, then percent mortalities were estimated and corrected according to Abbott's formula [26]. Probit analysis [27] was performed to estimate toxicity values (e.g., LD50 \& LD95) and slope of regression lines; using LD-P Software program.

\section{Analysis of the Plant Oil}

The obtained oil from $C$. aegyptiaca was subjected to Gas Chromatography/Mass Spectrometry analysis (GC/MS) coupled to a HP5973 mass-spectrometer to identify its chemical constituents. Samples of $0.5 \mu \mathrm{l}$ of the essential oil diluted in n-hexane were injected manually in the splittless mode into Hewlett Packard Chromatograph Model 5970, equipped with flame ionization detector (FID) and 20 meter HP capillary column $(0.2 \mathrm{~mm}$ I.D. $)$. The oven temperature was programmed at $3{ }^{\circ} \mathrm{C} / \mathrm{min}$. from $60^{\circ} \mathrm{C}$ to $200{ }^{\circ} \mathrm{C}$, and then isothermally at $200{ }^{\circ} \mathrm{C}$ for $25 \mathrm{~min}$. Detector and injector temperatures were $250^{\circ} \mathrm{C}$ and $200^{\circ} \mathrm{C}$, respectively. Helium was used as carrier gas at a constant flow of $1.0 \mathrm{~mL} \mathrm{~min}$. The MS scan parameters included electron impact ionization voltage of $70 \mathrm{eV}$, a mass range of $40-750 \mathrm{~m} / \mathrm{z}$ and a scan interval of $0.5 \mathrm{~s}$. The identification of the components was based on comparison of their mass spectra with those of NIST3.0 Libraries provided with the computer-controlling GC-MS system as well as from the published literature.

\section{RESULTS}

Mortalities resulted from exposing the larvae and adults of Anopheles pharoensis to different concentrations of Conyza aegyptiaca oil is presented in Table 1. Mortalities in either larval or adult stages of the tested mosquito occurred in a concentration- dependent manner. Exposure of mosquito larvae to a range of concentrations (20-70 ppm) induced mortalities ranged between $20-90 \%$. In mosquito adults, the oil concentration of $0.07 \mathrm{mg} / \mathrm{cm}^{2}$ caused ca. $21 \%$ mortality which was increased gradually up to $91.7 \%$ at a concentration equivalent to $0.12 \mathrm{mg} / \mathrm{cm}^{2}$ (Table $\mathbf{1}$ ).

In housefly tests, mortalities in either larval or adult stages of the tested $M$. domestica insect were also occurred in a concentration- dependent manner. Complete mortality $(100 \%)$ in housefly larvae occurred from exposing to bait containing oil at a concentration of 110 ppm (Table 2). Topical application for the housefly adults by $0.16 \mu \mathrm{g}$ plant oil to each insect achieved $95.7 \%$ mortality.

The obtained concentration- mortality data (Table 1) enabled us to estimate the toxicity values of $C$. aegyptiaca oil against both insects as shown in (Table 3). It appeared that the oil possessed LC50 and LC95 values accounting to 37.8 and $108.7 \mathrm{ppm}$, respectively against the mosquito larvae; values extrapolated from a regression line of 3.6 slope. Such toxicity values in case of the mosquito adults were 0.087 and $0.133 \mathrm{mg} / \mathrm{cm}^{2}$, respectively for LC50 and LC95 derived from a regression line of 9.1 slope value.

By the same manner the obtained concentration- mortality data (Table 2) revealed the following toxicity values for

Table 1. Mortalities Resulted from Exposing of $4^{\text {th }}$ Instar Larvae and Adult Females of Anopheles pharoensis to Different Concentrations of Conyza aegyptiaca Oil

\begin{tabular}{|c|c|c|c|}
\hline Concn. (ppm) & \%Mortality Against Larvae & Concn. $\left(\mathbf{m g} / \mathbf{c m}^{\mathbf{2}}\right.$ ) & \%Mortality Against Adults \\
\hline \hline Cont. & 0.0 & Cont. & 0.0 \\
20 & 20.0 & 0.07 & 33.7 \\
30 & 35.9 & 0.08 & 56.0 \\
40 & 47.1 & 0.09 & 68.7 \\
50 & 60.0 & 0.10 & 80.0 \\
70 & 77.3 & 0.11 & 91.7 \\
\hline
\end{tabular}


Table 2. Mortalities Resulted from Exposing $4^{\text {th }}$ Instar Larvae and Adult Stage of Musca domestica to Different Concentrations of Conyza aegyptiaca Oil

\begin{tabular}{|c|c|c|c|}
\hline Concn. (ppm) & \%Mortality Against Larvae & Concn. ( $\mu \mathrm{g} / \mathrm{insect})$ & \%Mortality Against Adults \\
\hline Cont. & 0.0 & Cont. & 0.0 \\
\hline 50 & 20.0 & 0.10 & 15.1 \\
\hline 60 & 33.7 & 0.11 & 27.3 \\
\hline 70 & 45.0 & 0.12 & 39.9 \\
\hline 80 & 57.9 & 0.13 & 50.3 \\
\hline 90 & 70.0 & 0.14 & 70.0 \\
\hline 100 & 83.1 & 0.15 & 81.3 \\
\hline 110 & 100.0 & 0.16 & 95.7 \\
\hline
\end{tabular}

Table 3. Toxicity Values for Conyza Aegyptiaca Oil Against Larvae and Adult Stages of An. pharoensis ${ }^{\text {a) }}$ and M. domestica $^{\text {b) }}$

\begin{tabular}{|c|c|c|c|c|c|}
\hline \multicolumn{3}{|c|}{ An. Pharoensis Larvae } & \multicolumn{3}{|c|}{ An. Pharoensis Adults } \\
\hline LC50 (ppm) & LC95 (ppm) & Slope $e^{\text {c) }}$ & $\operatorname{LC50}\left(\mathrm{mg} / \mathrm{cm}^{2}\right)$ & LC95 (mg/cm²) & Slope ${ }^{c)}$ \\
\hline 37.8 & 108.7 & 3.6 & 0.087 & 0.133 & 9.1 \\
\hline \multicolumn{3}{|c|}{ M. Domestica Larvae } & \multicolumn{3}{|c|}{ M. Domestica Adults } \\
\hline LC50 (ppm) & LC95 (ppm) & Slope $e^{\text {c) }}$ & LD50 ( $\mu \mathrm{g} /$ insect $)$ & LD95 ( $\mu \mathrm{g} /$ insect $)$ & Slope ${ }^{\text {c) }}$ \\
\hline 71.8 & 139.3 & 5.7 & 0.125 & 0.172 & 11.9 \\
\hline
\end{tabular}

${ }^{\text {a) }}$ Data refer to Table 1.

b) Data refer to Table 2 .

${ }^{c)}$ Slope of regression line.

the tested oil against the housefly (Table 3):

I. Larval toxicity values: $\mathrm{LC} 50=71.8 \mathrm{ppm}$; $\mathrm{LC} 95=139.3$ ppm; slope value $=5.7$.

II. Adult toxicity values: $\mathrm{LD} 50=0.125 \mu \mathrm{g} /$ insect; LD95 $=$ $0.172 \mu \mathrm{g} /$ insect; slope value $=11.9$.

In the present study, we identified 19 compounds constituting ca. $97 \%$ of phytochemicals present in the oil, such as monoterpenes, sesquiterpenes and esters. It was found that limonene constitutes about $50 \%$ of the plant oil $(48.79 \%)$, followed by (E) - $\beta$-Ocimene (8.66\%), Germacrene D (7.54\%) and $\beta$-pinene (6.91\%). The occurrence of the other constituents ranged between $0.27 \%$ and $5.29 \%$ (Table 4 ).

\section{DISCUSSION}

Conyza aegyptiaca is one of the most used plants to treat malaria in Rwandan traditional medicine. It is also used in the treatment of haematuria [28]. The author reported that methanolic leaf extract of the plant showed a moderate an- tiplasmodial activity (IC50 $=22.7 \mu \mathrm{g} / \mathrm{ml}$ ) and was slightly more active than the dichloromethane leaf extract $($ IC50 $=$ $36.8 \mu \mathrm{g} / \mathrm{ml})$. The methanolic leaf extract showed a low cytotoxicity (IC50 $=80.9 \mu \mathrm{g} / \mathrm{ml}$ ) but presented a low selectivity index (3.6). To the best of our knowledge, however, the literature offers no data on the insecticidal activity of C. aegyptiaca oil, a matter which was targeted in the present study in an attempt to fill a gap in this direction.

Essential oils and their volatile constituents are widely used in the prevention and treatment of human illnesses. They are also documented for exhibition of acute toxicity, anti-feeding and oviposition deterrents against a wide variety of insect-pests [29, 30]. Certain plant species containing essential oils have proved efficacy as larvicides, adulticides, ovicides and repellents against different species of mosquitoes [31-36]. The lower risk level of the volatile essential oils to the environment and their minimal residual activity against predator, parasitoid and pollinator insect populations, making essential-oil-based pesticides compatible with integrated pest management programs [30,37]. 
Table 4. GC/MS Analysis of Conyza aegyptiaca Oil

\begin{tabular}{|c|c|c|c|c|c|}
\hline No. & Chemical Name & Retention Time (min) & Peak Area (\%) & Chemical Formula & Molecular Weight \\
\hline 1 & $\alpha$-pinene & 7.18 & 0.90 & $\mathrm{C}_{10} \mathrm{H}_{16}$ & 136 \\
\hline 3 & $\beta$-pinene & 8.04 & 6.91 & $\mathrm{C}_{10} \mathrm{H}_{16}$ & 136 \\
\hline 4 & Myrcene & 8.72 & 1.64 & $\mathrm{C}_{10} \mathrm{H}_{16}$ & 136 \\
\hline 6 & (Z)- $\beta$-Ocimene & 9.82 & 0.27 & $\mathrm{C}_{10} \mathrm{H}_{16}$ & 136 \\
\hline 7 & (E)- $\beta$-Ocimene & 10.03 & 8.66 & $\mathrm{C}_{10} \mathrm{H}_{16}$ & 136 \\
\hline 8 & (E)-Caryophyllene & 10.41 & 4.36 & $\mathrm{C}_{15} \mathrm{H}_{24}$ & 204 \\
\hline 11 & Germacrene D & 15.94 & 7.54 & $\mathrm{C}_{15} \mathrm{H}_{24}$ & 204 \\
\hline 12 & Bicyclogermacrene & 16.21 & 5.29 & $\mathrm{C}_{15} \mathrm{H}_{24}$ & 204 \\
\hline 13 & $\delta$-Candinene & 16.40 & 3.54 & $\mathrm{C}_{15} \mathrm{H}_{24}$ & 204 \\
\hline 14 & Trans-Nerolidol & 17.45 & 1.02 & $\mathrm{C}_{15} \mathrm{H}_{26} \mathrm{O}$ & 222 \\
\hline 15 & Germacrene D4-ol & 17.53 & 0.91 & $\mathrm{C}_{15} \mathrm{H}_{26} \mathrm{O}$ & 222 \\
\hline 16 & Spathulenol & 18.31 & 1.64 & $\mathrm{C}_{15} \mathrm{H}_{24} \mathrm{O}$ & 220 \\
\hline 17 & Caryophyllene oxide & 19.35 & 2.06 & $\mathrm{C}_{15} \mathrm{H}_{24} \mathrm{O}$ & 220 \\
\hline \multicolumn{3}{|c|}{ Total identified peak area $\%$} & \multicolumn{3}{|c|}{$96.99 \%$} \\
\hline
\end{tabular}

Phytochemical investigations on C. aegyptiaca have led to the isolation of diterpenes [38]; triterpenes [39, 40]; sesquiterpenes [38, 41, 42]; flavonoids [43, 44]; and Phloroglucinol Glucoside derivative, roseoside and kaempferol-3-O- $\beta$ D-glucopyranoside [45] from the aerial parts of the plant. In the present study, we identified some phytochemicals present in the oil. As mentioned above, the triterpene limonene constituted about $50 \%$ of the plant oil $(48.79 \%$ ) (Table 4). This may give an indication that $C$. aegyptiaca is a limonene-rich plant, compared with some other plants. For instance, essential oil of dill seeds was reported to be $9.34 \%$ [46]; and (44.1\% or $16.6 \%$ or $16.0 \%$ ) in Anethum graveolens seeds; according to results published by other investigators [47-49]. But citrus limonene exceeded these levels, and was reported to range between $51.97 \%$ in Sour Orange oil and $95.32 \%$ in Lime oil [36].

The insecticidal activity of plant oils was extensively referred to limonene content in the essential oils [36, 50-52]. Both Kassir et al. [53] and Mohsen et al. [54] reported the larvicidal action of limonene against the larvae of Cx. quinquefasciatus. According to Mansour et al. [36], the Lime peel oil of $95.32 \%$ limonene content showed the highest toxicity against Culex pipiens larvae (LC50 $=77.6 \mathrm{ppm})$, while
Sour Orange peel oil of $51.97 \%$ limonene content exhibited the lowest toxicity $(\mathrm{LC} 50=136.4 \mathrm{ppm})$. This dose-dependent trend was not fully obvious with the results obtained from the adulticidal tests. For example, Mandarin peel oil of $73.11 \%$ limonene content showed LC50 of $0.105 \mathrm{mg} / \mathrm{cm}^{2}$, compared to $0.155 \mathrm{mg} / \mathrm{cm}^{2}$ for Grapefruit peel oil which contained $93.08 \%$ limonene. In a comparison held between toxicity of limonene alone with the citrus peel oils, it was concluded that limonene alone has a basic biocidal properties against the tested insect, but its potency can be improved considerably when being in the oil extracted from citrus peels; due to possible synergistic interaction with the other compounds in the oil (Mansour et al., 2004).

From the above mentioned, we suggest that the obtained toxicity results of $C$. aegyptiaca-essential oil may refer to limonene which was dominated above all the other detected compounds. Limonene, as a pure compound was reported to possess LC50 of $126.1 \mathrm{ppm}$ and LC50 of $0.165 \mathrm{mg} / \mathrm{cm}^{2}$, respectively against larvae and adult stages of Culex pipiens mosquitoes [36]. According to the results of the present investigation, the essential oil from $C$. aegyptiaca showed superior toxicity against the larvae $(\mathrm{LC} 50=71.8 \mathrm{ppm}$; Table 3 ) and the adults (LC50 $=0.087 \mathrm{mg} / \mathrm{cm}^{2}$; Table 3) of $A n$. 
pharoensis. Such results may be attributed to different susceptibility of both mosquito species, as well as different compositions of the tested substances in both cases compared and possible synergistic action exhibited by the oil rather than the pure compound limonene; based on Mansour et al. [36].

The results in Table 3 indicate that the slope values equaled 3.6 and 5.7 in larvicidal tests with An. pharoensis and $M$. domestica, respectively. Such values equaled 9.1 and 11.9 , respectively in the adulticidal tests. Simply, these slope values indicate that the larval and adult stages of $M$. domestica are more vulnerable than the larval and adult stages of An. pharoensis to the toxic action of C. aegyptiaca oil. According to Busvine [55], with a steep regression line (i.e., of high slope value), the test insect shows obvious response to each little increase of the toxic dose, and the opposite with a regression line of low slope value. Also, as high slope of a regression line as more homogeneity of the tested insect population to the tested toxicant.

In conclusion, the results of the present study provide new data focusing on the insecticidal efficacy of the essential oil extracted from the native herb, Conyza aegyptiaca, against pests of medical importance such as mosquitoes and housefly. The potency may refer mainly to the presence of limonene in the oil. Such findings may encourage more research aiming at investigation of eco-friendly biopesticides based on botanical resources.

\section{CONFLICT OF INTEREST}

The authors declared no conflict of interest.

\section{ACKNOWLEDGEMENT}

None Declared.

\section{REFERENCES}

[1] Ande AT. Biological activities of some plant materials against the housefly- Musca domestica. Nigerian Soc Exp Biol J 2001; 1(4): 293-6.

[2] Khan MF, Ahmed SM. Toxicity of crude neem leaf extract against houseflies Musca domestica adult as compared with DDVP, dichlorvos. Turk J Zool 2000; 24: 219-23.

[3] Douglass ES, Jesse C. Integrated pest management for fly control in Maine dairy farms. US : Texas Agricultural Extension Service 2002; p. 46.

[4] Mian LS, Maag H, Tacal JV. Isolation of Salmonella from muscoid flies at commercial animal establishments in San Bernardino County, California. J Vector Ecol 2002; 27(1): 82-5.

[5] Barin A, Arabkhazaeli F, Rahbari S, Madani S. The house fly, Musca domestica, as a possible mechanical vector of Newcastle disease virus in the laboratory and field. Med Vet Entomol 2010; 24: 88-90.

[6] Sagar SK, Schgal S. Toxicity of neem seed coat extract against mosquitoes. Ind J Entomol 1997; 59: 215-33.

[7] Cao MX, Song FL, Zhao TY, Dong YD, Sun CHX, Lu BL. Survey of Deltamethrin resistance in houseflies (Musca domestica) from urban garbage dumps in Northern China. Environ Entomol 2006; 35(1): $1-9$

[8] Malik A, Singh, N, Satya S. Housefly (Musca domestica): A review of control strategies for a challenging pest. J Environ Sci Health B 2007; 42: 453-69.

[9] Ahmed SM, Chander H, Pereira J. Insecticidal potential and biological activity of India indigenous plants against Musca domestica. Int Pest Control 1981; 23: 170-5.
[10] Georghiou GP , Mellon R. Pesticide resistance in time and space. In: Georghiou GP, Saito T, Eds. Pest Resistance to Pesticides. Plenum Press: New York 1983; pp. 1-46.

[11] Scott JG, Alefantis TG, Kaufman PE, Rutz DA. Insecticide resistance in house flies from caged-layer poultry facilities. Pest Manage Sci 2000; 56: 147-53.

[12] Belmain SR, Neal GE, Ray D, Golob P. Insecticidal and vertebrate toxicity associated with ethnobotanicals used as postharvest protectants in Ghana. Food Chem Toxicol 2001; 39: 287-91.

[13] Dhar R, Dawar H, Garg S. Effect of volatiles from neem and other natural products on gonotrophic cycle and oviposition of Anopheles stephensi and An. Culicifacies (Diptera: Culicidae). J Med Entomol 1996; 33: 195-201.

[14] Promsiri S, Naksathit A, Kruatrachue M, Thavara U. Evaluation of larvicidal activity of medicinal plant extracts to Aedes aegyti (Diptera: Culicidae) and other effects on a non target fish. Insect Sci 2006; 13: 179-88.

[15] Beentje HJ. Flora of tropical East Africa.vol. 1. London: CRC Press 2002; p. 315

[16] Chai X, Su YF, Gua LP, et al. Phenolic constituents from Conyza sumatrensis. Biochem Syst Ecol 2008; 36: 216-8.

[17] Burkill HM. The useful plants of west tropical Africa, vol. 1. Kew: Royal Botanica Gardens, 1985.

[18] Anani K, Hudson JB, De Souza C, et al. Investigation of medicinal plants of Togo for antiviral and antimicrobial activities. Pharm Biol 2000; 38: 40-5.

[19] Mansour SA, Bakr RFA, Hamouda LSA, Mohamed RI. Toxic and synergistic properties of several botanical extracts against larval and adult stages of the mosquito, Anopheles pharoensis. Biopestic Int 2010; 6(2): 129-45

[20] Mansour SA, Bakr RFA, Mohamed RI, Hasaneen NM. Larvicidal activity of some botanical extracts, commercial insecticides and their binary mixtures against the housefly, Musca Domestica L. Open Toxinol J 2011; 4: 1-13.

[21] Mansour SA, Bakr RFA, Hamouda LS, Mohamed RI. Adulticidal activity of some botanical extracts, commercial insecticides and their binary mixtures against the housefly, Musca domestica L. Egypt Acad J Biol Sci Entomol 2012; 5(1):151-67.

[22] Kasap M Demirhan O. The effect of various larval foods on the rate of adult emergence and fecundity of mosquitoes. Turk Parazitol Derg 1992; 16: 87-97.

[23] Sawicki RM. Some general considerations of housefly rearing techniques. Bull WHO 1964; 31: 535-7.

[24] Anderson BA, Holman RT, Lundgren L, Stenhagen G. Capillary gas chromatography of leaf volatiles. A possible aid to breeders for pest and disease resistance. J Agric Food Chem 1980; 28: 985-9.

[25] Wright JW. The WHO programme for the evaluation and testing of new insecticides. Bull World Health Organ 1971; 44: 11-2.

[26] Abbott WS. A method of computing effectiveness of an Insecticide. J Econ Entomol 1925; 18: 265-7.

[27] Finney DJ. Probit analysis. $2^{\text {nd }}$ ed. Cambridge : Cambridge University Press 1971; p. 333.

[28] Rwangabo PC. La m'edicine traditionnelle au Rwanda. ACCT : Karthala 1993.

[29] Rice PJ, Coats JR. Insecticidal properties of several monoterpenoids to the house fly Diptera: Muscidae), red flour beetle (Coleoptera: Tenebrionidae), and southern corn rootworm (Coleoptera: Chrysomelidae). J Econ Entomol 1994; 87(5): 1172-9.

[30] Tripathi AK, Upadhyay S, Bhuiyan M, Bhattacharya PR. A review on the prospects of essential oils as biopesticides in insect pestmanagement. J Pharm Phytother 2009; 1(15): 52-63.

[31] Hwang YS, Wu KH, Kumamota J, Axelored H, Mulla MS. Isolation and identification of mosquito repellents in Artemisia vulgaris. J Chem Ecol 1985; 11(9): 1297-306.

[32] Sharma VP, Nagpal BN, Srivastava A. Effectiveness of neem oil mats in repelling mosquitoes. Trans R Soc Trop Med Hyg 1993; 87(6): 626-9.

[33] Ansari MA, Razdan RK. Repellent action of Cymbopogon martini staf var. Sofia [sic] oil against mosquitoes. Ind J Malariol 1994; 31(3): 95-102.

[34] Mansour SA, Messeha SS, Mohamed SM. Botanical Biocides. 5. Mosquitocidal activity of certain Nigella sativa constituents. J. Union Arab Biol 1998; 10(A): 45-63.

[35] Mansour SA, Messeha SS, El-Gengaihi SE. Botanical Biocides. 4. Mosquitocidal activity of certain Thymus capitatus constituents. J Nat Toxins 2000; 9(1): 49-62. 
[36] Mansour SA, El-Sharkawy AZ, Ali AR. Botanical Biocides. 12. Mosquitocidal activity of citrus peel oils with respect to their limonene content. Egypt J Nat Toxins 2004; 1: 111-34.

[37] Isman MB. Botanical insecticides, deterrents, and repellents in modern agriculture and an increasingly regulated world. Annu Rev Entomol 2006; 51: 45-66.

[38] Zdero C, Ahmed AA, Bohlmann F, Mungai GM. Diterpenes and sesquiterpene xylosides from East Africa Conyza species. Phytochemistry 1990; 29: 3167-72.

[39] Metwally MA. New triterpene from Conyza aegyptiaca L. Z Naturforsch 1989; 44b:1584.

[40] Hammouda FM, Rizk AM, El-Nasr MM, El-Kady SEM. Phytochemical investigation of Conyza dioscoridis and $C$. aegyptiaca. Fitoterapia 1978; 49: 51-2.

[41] Metwally MA, Dawidar AAM. Constituents of Conyza aegyptiaca L. Pak J Sci Ind Res 1984; 27: 213-4.

[42] Metwally MA, Dawidar AAM. Constituents of Conyza aegyptiaca L. Pharmazie 1984; 38: 575-6.

[43] El-Karemy ZAR, Mansour RMA, Fayed AA, Saleh NAM. The flavonoids of local members of Asteraceae (Compositae). Biochem Syst Ecol 1986; 15: 53-5.

[44] Ismail SI, Hammouda FM, Rizk AM, El-kady S. Flavonoid constituents of Conyza dioscoridis L. and Conyza aegyptiaca Ait. Pharmazie 1979; 34: 112.

[45] Mahmoud A, Al-Shihry SS, Hegazy MF. Biological activity of a phloroglucinol glucoside derivative from Conyza aegyptiaca. Z. Naturforsch 2009; 64c: 513-7.

[46] Asraf M, Aziz J, Bhatty MK. Studies on the essential oils of the Pakistani species of the family Umbelliferae. Part VI. Anethum graveolens (Dill, Sowa) seed oil. Pak J Sci Ind Res 1977; 20(1): $52-4$.

[47] Jirovetz L, Buchbauer G, Stoyanova AS, Georgiev EV, Damianova ST. Composition, quality control and antimicrobial activity of the essential oil of long time stored dill (Anethum graveolens L.) seeds from Bulgaria. J Agric Food Chem 2003; 18: 3854-7.

[48] Singh G, Maurya S, Lampasona MPD, Catlan C. Chemical constituents, antimicrobial investigations, and antioxidative potentials of Anethum graveolens L. Essential oil and acetone extract: part 52. J Food Sci 2005; 70(4): M208-M215.

[49] Babri RA, Khokhar I, Mahmood Z, Mahmud S. Chemical composition and insecticidal activity of the essential oil of Anethum graveolens L. Sci Int (Lahore) 2012; 24(4): 453-5.

[50] Ibrahim MA., Kainulainen P, Aflatuni A, Tiilikkala K, Holopainen JK. Insecticidal, repellent, antimicrobial activity and phytotoxicity of essential oils: with special reference to limonene and its suitability for control of insect pests (Review) Agric Food Sci Fin 2001; 10: 243-59.

[51] Hollingsworth RG. Limonene, a citrus extract, for control of mealybugs and scale insects. J Econ Entomol 2005; 98(3): 772-9.

[52] Sfara V, Zerba EN, Alzogaray RA. Fumigant insecticidal activity and repellent effect of five essential oils and seven monoterpenes on first-instar nymphs of Rhodnius prolixus. J Med Entomol 2009; 46: 511-5.

[53] Kassir JT, Mohsen ZH, Mehdi NS. Toxic effect of limonene against Culex quinquefasciatus Say larvae and its interference with oviposition. Anzeiger Schadlingskunde Pflanze-Nschutz Umweltschutz 1989; 62(1): 19-21.

[54] Mohsen ZH, Al-Chalabi BM, Kassir JT, Chalabi BMAL. Factors influencing the larvicidal activity of limonene against Culex quinquefasciatus. J Appl Entomol 1989; 108(1): 107-10.

[55] Busvine JR. A critical review of the techniques for testing insecticides. London: The Commonwealth Institute of Entomology 1971; p. 345.

(C) Mansour and Mohamed; Licensee Bentham Open.

This is an open access article distributed under the terms of the Creative Commons Attribution License (http://creativecommons.org/licenses/by/2.5/), which permits unrestrictive use, distribution, and reproduction in any medium, provided the original work is properly cited. 